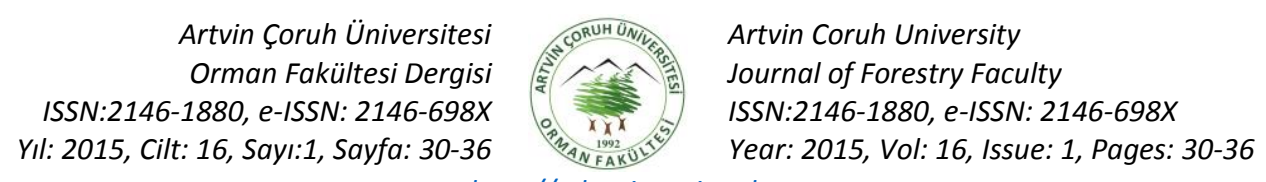

http://edergi.artvin.edu.tr

Araştırma makalesi

\title{
Plumbago europaea L.' nın besinsel, antioksidan ve antimikrobiyal aktivitesinin belirlenmesi
}

Nutritive value, antioxidant and antimicrobial activitiy of Plumbago europea $\mathrm{L}$.

Burak BiRCAN ${ }^{1}$, Sevda KIRBA $\breve{G}^{2}$

${ }^{1}$ Fırat Üniversitesi, Fen Bilimleri Enstitüsü, Biyoloji Bölümü

${ }^{2}$ Fırat Üniversitesi, Fen Fakültesi, Biyoloji Bölümü

Özet

Bu çalışmada; $P$. europea'nın besinsel içerikleri, antioksidan ve antimikrobiyal etkileri araştırıldı. Şeker, flavonoid, vitamin ve mineral element düzeylerinin değişebildiği gözlendi. In vitro koşullarda, DPPH radikalini temizleme aktivitesinin $10 \mu \mathrm{g} / \mu \mathrm{L}^{\prime} \mathrm{de}$ \%83.62, FeCl grubunun K grubuna göre yüksek ve metil esterlerinin ise korunmadığı belirlendi. $P$. europea'nın antimikrobiyal aktivitesinin ise; maya ve dermofit funguslardan ziyade, bakteri gruplarında daha etkili olduğu saptandı.

Anahtar kelimeler: Antimikrobiyal aktivite, antioksidan, besinsel içerik, P. europea

Abstract

In this study, nutritive value, antioxidant and antimicrobial activitiy of $P$. europea was determined. It was observed that sugar, flavonoid, vitamin and element levels varied. It was understood that under in vitro conditions the DPPH activities had a level of $83.62 \%$ at $10 \mu \mathrm{g} / \mu \mathrm{L}$, the $\mathrm{FeCL}$ group was higher than the $\mathrm{K}$ group, and the methyl esters were not preserved as well. It was also determined that the antimicrobial activity of $P$. europea is more efficent over bacterial groups then yeast and dermatophyte fungi.

Keywords: Antimicrobial activity, antioxidant activity, nutritive value, P. europea

\section{GíRiş}

Dünyanın değişik ülkelerinde olduğu gibi, ülkemizde de tıbbi açıdan önemli bulunan değişik yenen ve yabani bitkiler yüzyıllardan beri halk arasında besinsel ve tedavi amaçlı kullanılmaktadır. Dünya sağlık teşkilatı (WHO)'nın 91 ülkenin kodeks ve tıbbi bitkileri üzerinde yapılmış olan bazı yayınlara dayanarak hazırladığı araştırmaya göre, tedavi amacıyla kullanılan tıbbi bitkilerin sayısının yaklaşık olarak 20.000 civarında olduğu, ancak 500 kadarının tarımsal üretiminin yapıldığı kaydedilmektedir. Ayrıca değişik amaçla kullanılan bitkilerin çok azı farmokopelerde kayıtlıdır. Türk kodeksinde kayıtlı bitki sayısı 140 civarındadır. Hâlbuki Türkiye de tıbbi amaçla tüketilen bitki sayısı çok fazladır, hatta bazı yayınlarda bunun en az 500 civarında olduğu kaydedilmektedir (Baytop 1984).

P.europea, Plumbaginaceae familyasına ait çok yıllık çiçekli bir bitki olup, halk arasında "kurşun otu, kuduzotu, dişotu, sıtmaotu ve döven otu" gibi isimlerle anılmaktadır. Plumbago cinsine ait değişik türlerin iltahap ve mikrobiyal hastalıkların tedavisinde kullanıldığı, aynı zamanda taksit etkilerinin olduğu rapor edilmiştir (Arunachalam, Velmurugan, ve Raja 2010). P.europea bitki yapraklarının; kan çıbanı tedavisi, diş ve romatizmal ağrıların giderilmesinde (Okoli, Akah, ve Ezugworie 2006), kök ve kök kabuklarının ise; basur, ishal, cüzzam gibi çeşitli cilt hastalıklarının tedavisinde kullanıldığı bildirilmektedir (Bulut ve Tuzlacı 2011; Uma, Soloman, ve Sharda 1999). Ayrıca, P.europea'nın kaynatıp-süzmek suretiyle hamile kalmak için kullandıkları saptanmıştır (Akan, Korkut, ve Balos 2008).

Bu çalışmada; P. europaea'nın; mineral element, şeker bileşenleri, flavonoid ve fitosterol içerikleri ile antioksidan ve antimikrobiyal etkilerinin ortaya çıkarılması amaçlanmıştır.

\section{MATERYAL VE METOT}

\section{Bitki Ekstraktlarının Eldesi}

Çalışmada kullanılan $P$. europaea L., Elazığ ilinden toplandı. Bitki örneği için $1 / 5(\mathrm{~g} / \mathrm{mL})$ oranında \%80'lik methanol ile ekstrakt hazırlandı. 


\section{Besinsel İçeriklerinin Saptanması}

\section{Şeker analizi}

P. europaea'dan alınan 1:1 (g/mL) oranında kreuze içine alınarak distile su ile iyice homojenize edildip süzülerek pellet ile sıvı kısım ayrıldı. Toplam filtratın hacmi belirlenerek RI dedektörünün bağlı olduğu HPLC cihazı ile analiz edildi (Chromatography A 2004; Erden, Kırbağ, ve Yılmaz 2013).

\section{Resveratrol ve flavonoid içeriğinin belirlenmesi}

Flavonoidlerin kromatografik analizi için $5 \mu \mathrm{m}$ iç çapında PREVAIL C18 $(15 \times 4.6 \mathrm{~mm})$ ters-faz kolon kullanıldı. Mobil faz olarak \%1 asetik asit içeren metanol/su/asetonitril (46/46/8, v/v/v) karışımı kullanıldı (Zu ve ark. 2006). Bu mobil faz $0.45 \mu \mathrm{m}$ membran filtresi süzülerek ultrasonikasyon cihazında havası alındı. Kateşin ve naringin için 280 nm, rutin, mirisetin, morin ve kuarsetin için $254 \mathrm{~nm}$, resveratrol için $306 \mathrm{~nm}$ ve kamferol için $265 \mathrm{~nm}$ dalga boyu kullanılarak RHPLC ayrımını takiben DAD tarafından bu flavonoidlerin ölçümü yapıldı.

\section{ADEK vitaminleri ve fitosterol miktarinin tespit edilmesi}

5 mL HIP karışımı 25 mL'lik ağzı kapaklı tüpler içine alınarak üzerine $5 \mathrm{~mL} 0.5 \mathrm{M} \mathrm{KOH}$ çözeltisi ilave edildi. Vortekslendikten sonra $85{ }^{\circ} \mathrm{C}^{\prime} \mathrm{de} 25 \mathrm{dk}$ bekletildi. Tüpler çıkartılarak oda sıcaklığına kadar soğutulup üzerine $5 \mathrm{~mL}$ saf su ilave edilerek karıştırıldı. Sabunlaşmayan lipofilik moleküller $2 \times 5 \mathrm{~mL}$ hekzan ile ekstrakte edildi. Hekzan fazı azot akımı ile uçuruldu. 1 $\mathrm{mL}$ (50:50, v/v) asetonitril/metanol karışımında çözülerek Shimadzu marka HPLC cihazı ile analiz edildi. Retinol ve türevleri için dedeksiyon dalga boyu $326 \mathrm{~nm}$, E vitamini ve fitosterol için $202 \mathrm{~nm}$, D ve $K$ vitaminleri için $265 \mathrm{~nm}$ 'de değerlendirildi (Lopez-Cervantes ve ark. 2006; Sanchez-Moreno ve ark. 1999).

\section{Mineral-element analizi}

Numune $105^{\circ} \mathrm{C}$ kuru hava sterilazatörü ile kurutuldu. Kuruyan numune havan kullanılarak öğütüldü. Örneğin çözme işlemini gerçekleştirmek için $\mathrm{HNO}_{3}: \mathrm{H}_{2} \mathrm{SO}_{4}: \mathrm{H}_{2} \mathrm{O}_{2}$ (1 g numune için 10:1:1, $12 \mathrm{~mL}$ ) karışımı kullanılarak $100^{\circ} \mathrm{C}$ de $10-15 \mathrm{dk}$ ısıl işleme maruz bırakıldı. Soğuyan numuneye $50 \mathrm{~mL}$ distile su eklendi. Filitre işlemi ile berrak bir çözelti elde edildi. $\mathrm{Fe}, \mathrm{Zn}, \mathrm{Mn}, \mathrm{Cu}, \mathrm{Cr}, \mathrm{Cd}, \mathrm{Co}$, $\mathrm{Ni}$ ve $\mathrm{Pb}$ miktarları otomatik absorbsiyon spektrofotometre kullanılarak (Perkin-Elmer Marka 370 Model), $\mathrm{K}, \mathrm{Mg}$, $\mathrm{Ca}$, ve $\mathrm{Na}$ elementleri ise otomatik emisyon spektrofotometre kullanılarak belirlendi (Eppendorf Geratebau) (Helrich 1990).

\section{Antioksidant Etkilerinin Tespit Edilmesi}

\section{Serbest radikal (DPPH) giderme aktivitesi}

Deney tüplerine sırasıyla 10, 25, 50, $100 \mu \mathrm{g} / \mu \mathrm{L}$ bitki ekstrakları ve DPPH $(25 \mathrm{mg} / \mathrm{L} \quad \alpha, \alpha$-Diphenylpicrylhydrazyl metanolde) çözeltisinden $3.9 \mathrm{~mL}$ ilave edildi. Karışımlar, oda sıcaklığında karanlık bir ortamda $30 \mathrm{dk}$ inkübasyona bırakıldıktan sonra absorbansları $517 \mathrm{~nm}$ 'de blanka karşı spektrofotometrede okundu (Brand-Williams, Cuvelier, ve Berset 1995; Hsu ve IM Coupar 2006).

Azalan absorbans, geriye kalan DPPH miktarı serbest radikal giderme aktivitesi olarak belirlendi. Sonuçlar aşağıdaki formüle göre hesaplandı.

$$
\%=\text { Kontrol }_{\mathrm{ABS}}-\text { Sample }_{\mathrm{ABS}} / \mathrm{Kontrol}_{\mathrm{ABS}} \times 100
$$

\section{In vitro ortamda antioksidan ve antiradikal aktivitenin belirlenmesi}

Bitki ekstraktının antioksidan aktivitesi, Shimoi ve ark.'nın yöntemine göre yapıldı (Shimoi ve ark. 1994). Bu amaçla; pH'sı 7.4 olan 0.05 M TRIS-HCl / $0.15 \mathrm{M} \mathrm{KCl}$ ve \%0.2 TWEEN 20 içeren tampon çözeltisi ile $1 \mathrm{mM}$ $\mathrm{FeCl}_{2}$ ve $3 \mu \mathrm{M}$ hidrojen peroksit günlük olarak hazırlandı. Bu tampon çözelti içerisinde $2.30 \mathrm{mM}$ Linolenik asit (LNA, 18:3 n-3), 10.44 mM Linoleik asit (LA, 18:2, n-6), 3.97 mM Oleik asit (18:1, n-9) çözeltileri DMSO'da çözünerek hazırlandı ve aşağıdaki deney grupları hazırlandı.

Kontrol grubu: $5 \mathrm{~mL}$ trisma-base tamponu, $0.4 \mathrm{~mL}$ yağ asidi karışımı 
$\mathrm{FeCl}_{2}+\mathrm{H}_{\mathbf{2}} \mathrm{O}_{\mathbf{2}}$ grubu: $5 \mathrm{~mL}$ trisma-base tamponu, $1 \mathrm{~mL}$ $\mathrm{FeCl}_{2}, 1 \mathrm{~mL} \mathrm{H} \mathrm{O}_{2}, 0.4 \mathrm{~mL}$ yağ asidi karışımı

Bitki: $5 \mathrm{~mL}$ trisma-base tamponu, $1 \mathrm{~mL} \mathrm{FeCl}, 1 \mathrm{~mL}$ $\mathrm{H}_{2} \mathrm{O}_{2}, 0.4 \mathrm{~mL}$ yağ asidi karışımı, $1 \mathrm{~mL}$ olmak üzere farklı miktarlarda bitki ekstraktı ilave edildi.

Bu gruplar $37^{\circ}{ }^{\prime}$ ' de 24 saat inkübasyondan sonra oda sıcaklığına gelmesi sağlandı ve gruplardaki örneklere \%4'lük BHT ilave edilerek daha ileri oksidasyon olması engellendi. Daha sonra örnek karışımlardan $1 \mathrm{~mL}$ alınarak lipid peroksidasyon düzeyi ölçüldü (Ronald ve ark. 2001; Erden ve Kırbağ 2013).

\section{In vitro ortamda lipid peroksidasyon (Ipo) ölçümü}

Örneklerden $1 \mathrm{~mL}$ alındıktan sonra üzerine \%0.6'।ık TBA çözeltisi ile $2 \mathrm{~mL}$ distile su ilave edilip vortekslendi. Daha sonra $90^{\circ} \mathrm{C}^{\prime}$ de $30 \mathrm{dk}$ bırakıp reaksiyon sonucu oluşan pembe renk $3 \mathrm{~mL}$ n-bütanol ile ekstrakte edildi. Örnekler santrifüj edildi ve santrifüj sonunda elde edilen supernatant kısmın yoğunluğu HPLC cihazında floresans dedektörle ölçüldü (Ronald ve ark. 2001).

\section{Antimikrobiyal Aktivitenin Belirlenmesi}

\section{Ekstrelerin hazirlanmasi ve test mikroorganizmalarin eldesi}

Çalışmada kullanılan mikroorganizmalar; (Staphylococcus aureus, Escherichia coli, Candida albicans, Epidermophyton spp.) Fırat Üniversitesi, Fen Edebiyat Fakültesi, Biyoloji Bölümü, Mikrobiyoloji Laboratuvarı kültür kolleksiyonundan karşılandı. Araştırmada bitkilerin kullanılan kısımlarından $10 \mathrm{~g}$ alınıp $200 \mathrm{~mL}$ metanol ilave edilip ekstraksiyona tabi tutuldu. Elde edilen ekstraktların çözücüleri rotavaporda uzaklaştırılarak ve etüvde kurutularak kuru ekstraktlar elde edildi. Kurutulan ekstraktlar metanolde çözdürüldü.

\section{Mikroorganizma Kültürlerinin Hazırlanması ve Aşılama}

Bakteri suşları; Nutrient Buyyon'a aşılanarak $35 \pm 1^{\circ} \mathrm{C}^{\prime}$ de 24 saat, maya suşları; Yeast Malt Ekstrakt Buyyon'da ve dermatofit funguslar Glukozlu
Sabouroud Buyyon' da $25 \pm 1^{\circ} \mathrm{C}^{\prime}$ de 48 saat süre ile inkübe edildi. Sıvı besiyerinde gelişen kültürler, Mc Farland (0.5) standart tüpüne göre yoğunluk ayarı yapıldıktan sonra buyyon tüplerine aktarıldı. Erlenmayerde steril edilen ve $45-50^{\circ} \mathrm{C}^{\prime}$ ye kadar soğutulan Müller Hinton Agar, Yeast Malt Ekstrakt Agar ve Sabouraud Dextrose Agar hazırlanıp bakteri, maya ve fungusların buyyondaki kültürü ile \%1 oranında aşılanarak $\left(10^{6}\right.$ bakteri $/ \mathrm{mL}, 10^{4}$ maya $/ \mathrm{mL}, 10^{4}$ fungus $/ \mathrm{mL}$ ) iyice çalkalandıktan sonra $9 \mathrm{~cm}$ çapındaki steril petri kutularına $15^{\prime} \mathrm{er} \mathrm{mL} \mathrm{konuldu} \mathrm{(Collins} \mathrm{ve} \mathrm{Lyne}$ 1987).

\section{Oyuk agar metodu}

Katılaşan agar üzerine $6 \mathrm{~mm}$ çapında açılan oyuklara bir damla besiyerinden sonra $10 \mu \mathrm{L}$ örnek aktarıldı. Bu şekilde hazırlanan petri kutuları $4^{\circ} \mathrm{C}^{\prime}$ de $1.5-2$ saat bekletildikten sonra bakteri aşılanan plaklar $37 \pm 1^{\circ} \mathrm{C}^{\prime}$ de 24 saat, maya ve dermatofit aşılanan plaklar ise $25 \pm 1^{\circ} \mathrm{C}^{\prime}$ de 3 gün süre ile inkübe edildi. Çalışma 3 paralel olarak yürütülerek ve sonuçlar ortalama değer olarak inhibisyon zonu $(\mathrm{mm})$ şeklinde değerlendirildi (Anonymous 1999).

\section{İstatistik Analizi}

İstatistik analizi için, standar istatistiksel paket programı kullanılmıştır. Kontrol grubu ile deneysel gruplar arasındaki karşılaştırma varyans analizi (ANOVA) ve LSD testleri kullanılarak yapılmıştır. Sonuçlar, 3 tekrarın ortalaması \pm standart sapması olarak olarak verilmiştir.

\section{BULGULAR VE TARTIŞMA}

\section{P. europea'nın Besinsel içeriklerinin Tespiti \\ P. europea'nın resveratrol ve flavonoid içeriği}

Tablo 1 'de görüldüğü gibi, $P$. europea'da rutin 23.65, mirisetin 3.65 , morin 0.35 , kuarsetin 0.17 , kateşin 1232.5, naringin $97.66 \mu \mathrm{g} / \mathrm{g}$ olarak değiştiği, fakat kamferol ve resveratrol ise tespit edilmedi. Total flavonoid içeriği $1362.67 \mu \mathrm{g} / \mathrm{g}$ olarak değiştiği saptandı (Tablo 1). Yüksek miktarda; rutin, kateşin ve naringin 
belirlendi (Tablo 1). Son yıllarda yapılan değişik çalışmalarda flavonoidler bakımından zengin bir beslenme ile kroner kalp hastalıkları ve kanser riskinin azaltılması arasında bir ilişki olduğunu göstermektedir (Hung ve ark. 2004; Tripoli ve ark. 2007). Flavonoid içeriğinin, bitkiden bitkiye göre hatta aynı bitkinin farklı (Justesen 2000). Flavonoidler bakımından zengin bir beslenmenin $A$ ve $C$ vitamininden bile daha güçlü antioksidan etkisi olduğu belirtilmiştir (SokółŁętowska, Oszmiański ve Wojdyło 2007). Değişik çalışmalarda ise, $P$. zeylanica'da total flavonoid içeriği $45.5 \mathrm{mg} \mathrm{GAE} / \mathrm{g}$ (Nile ve Khobragade 2010) ve total fenolik içeriği 109 mg/g olarak belirlenmiştir (Zahin, Aqil, ve Ahmad 2009). P. europea yapraklarında ise yeni bir flavonol olan 7-O-methylmyricetin (europetin) maddesi tespit edilmiştir (Harborne 1967).

\section{Şeker analizi}

P. europea'da; arabinoz 29.55, glukoz 342.8, fruktoz 704.71, sakkaroz 233.37 ve maltoz $233.42 \mu \mathrm{g} / \mathrm{g}$ olarak değiştiği ve fruktoz miktarının diğer şeker bileşenlerine oranla daha yüksek olduğu saptanmıştır (Tablo 1 ). organlarında bile değişiklik gösterdiği ifade edilmiştir

Değişik çalışmalarda ise ( $P$. zeylanica ve $P$. rosea bitkilerinin kök kabuğundan) fruktoz ve glukoz miktarının değiştiği belirlenmiştir (Pawar ve ark. 2011).

\section{Vitaminler ve fitosterol içeriği}

Tablo 1'de görüldüğü gibi, $P$. europea'da yüksek miktarda ergesterol (11.53 $\mu \mathrm{g} / \mathrm{g}$ ), $\beta$-sitosterol (8.54 $\mu \mathrm{g} / \mathrm{g}$ ve $\alpha$-Tokoferol $(2.93 \mu \mathrm{g} / \mathrm{g})$ saptanmıştır. Gaz kromatografisi-kütle spektrometrisi (GC-MS) analizi ile $P$. zeylanica'da; alkaloidler, tanen, steroidler, flavonoidler, saponinler, antrakinonlar, ve karbonhidratların bulunduğu rapor edilmiştir (Ajayi ve ark. 2011). Elde edilen verilerin değişebilir olduğu, bunun temel nedenininde farklı türlerden kaynaklanmaktadır.

\section{Element içeriği}

Tablo 1' de görüldüğü gibi, P. europea' da $3.23 \mathrm{mg} / \mathrm{g} \mathrm{Ca}$, $0.04 \mathrm{mg} / \mathrm{g} \mathrm{Zn}, 8.16 \mathrm{mg} / \mathrm{g} \mathrm{Na}, 240.5 \mathrm{~K} \mathrm{mg} / \mathrm{g}, 0.06 \mathrm{mg} / \mathrm{g}$ Fe ve $\mathrm{Mn}$ ile $0.18 \mathrm{mg} / \mathrm{g} \mathrm{Mg}$ belirlenmiştir. Yüksek miktarda $\mathrm{Na}$ ve $\mathrm{Ca}$ ihtiva ettiği görülmüştür. $P$. zeylanica'nın element içeriği araştırılmış ve benzer sonuçlar elde edilmiştir (Wang ve ark. 2014).

\begin{tabular}{|c|c|c|c|c|c|c|c|}
\hline $\begin{array}{c}\text { Flavonoid/ } \\
\text { Gruplar }\end{array}$ & $(\mu \mathrm{g} / \mathrm{g})$ & $\begin{array}{c}\text { Lipofilik } \\
\text { vitaminler ve } \\
\text { Fitosteroller }\end{array}$ & $(\mu \mathrm{g} / \mathrm{g})$ & $\begin{array}{l}\text { Şeker } \\
\text { İçeriği }\end{array}$ & $(\mu \mathrm{g} / \mathrm{g})$ & $\begin{array}{l}\text { Mineral } \\
\text { İçeriği }\end{array}$ & $(\mathrm{mg} / \mathrm{g})$ \\
\hline Rutin & $23.61 \pm 4, .28$ & Vitamin $\mathrm{K}_{1}$ & $0.62 \pm 0.05$ & Arabinoz & $29.55 \pm 2.62$ & $\mathrm{Ca}$ & $3.23 \pm 0.4$ \\
\hline Mirisetin & $3.65 \pm 0.15$ & Retinol & $0.24 \pm 0.03$ & Fruktoz & $704.71 \pm 4.36$ & $\mathrm{Zn}$ & $0.04 \pm 0.01$ \\
\hline Morin & $0.35 \pm 0.20$ & Vitamin D & $0.673 \pm 0.07$ & Glukoz & $342.8 \pm 1.58$ & $\mathrm{Na}$ & $8.16 \pm 1.02$ \\
\hline Kuarsetin & $0.17 \pm 0.1$ & $\alpha$ Tokoferol & $2.93 \pm 0.06$ & Sakkaroz & $233.37 \pm 1.02$ & K & $240.49 \pm 2.56$ \\
\hline Resveratrol & - & Ergosterol & $11.526 \pm 0.17$ & Maltoz & $233.42 \pm 0.96$ & $\mathrm{Fe}$ & $0.06 \pm 0.01$ \\
\hline Kateşin & $1232.5 \pm 6.72$ & Stigmasterol & - & & & $\mathrm{Mn}$ & $0.06 \pm 0.02$ \\
\hline Naringin & $97.66 \pm 1.01$ & $\beta$-sitosterol & $8.543 \pm 0.57$ & & & $\mathrm{Mg}$ & $0.18 \pm 0.04$ \\
\hline Kamferol & - & & & & & & \\
\hline Toplam & $1362.67 \pm 7.02$ & & & & & & \\
\hline
\end{tabular}

\section{P. europea'nın Antioksidant Aktivitesinin Belirlenmesi}

\section{P. europea'nın DPPH radikalini giderme aktivitesi}

P. europea'nın 10, 25, 50, $100 \mu \mathrm{g} / \mu \mathrm{L}$ olarak artan konsantrasyonlarda DPPH radikalini temizleme aktivitesi belirlenmiş ve $10 \mu \mathrm{g} / \mu \mathrm{L}^{\prime}$ de $\% 83.62$ 'lik en yüksek etkiyi göstermiştir (Şekil 1). Değişik çalışmalarda ise, $P$. europea' da ABTS $13.92 \pm 0.05$ $\mathrm{mg} / \mathrm{mL}$, DPPH ise $19.82 \pm 0.05 \mathrm{mg} / \mathrm{mL}$ olarak belirlenmiştir (Serrilli ve ark. 2010). P. zeylanica' nın ise kök ekstraktlarının DPPH radikalini temizleme aktivitesi $96 \mu \mathrm{L} / \mathrm{mL}$ olarak bildirilmiştir (Nile ve Khobragade 2010). Elde edilen sonuçların değişebilir olduğu, bunun temel nedeninin ise değişik türlerden kaynaklandığı tespit edilmiştir. 


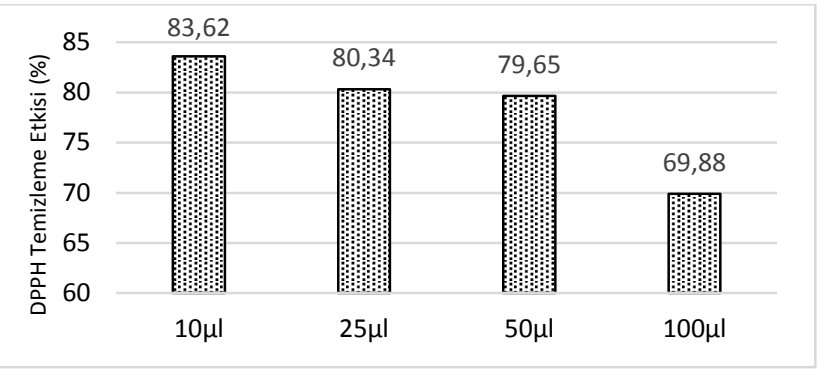

Şekil 1. P.europea' nın DPPH radikalini giderme aktivitesi (\%).

\section{P. europea'nın In vitro Ortamdaki Antioksidan Etkileri}

Şekil 2'de görüldüğü gibi, bitki ekstraktının in vitro ortamda lipid peroksidasyonu üzerine antioksidan etkileri incelendiğinde $\mathrm{FeCl}$ grubunun $\mathrm{K}$ grubuna göre oldukça yüksek olduğu ve bu düzeyin $\mathrm{FeCl}$ grubuna göre önemli düzeyde azaldığı tespit edildi $(p<0.05)$. Çalışmada kullanılan $P$. europea'nın in vitro ortamda insan yaşamını en fazla etkileyen dejenaratif metabolik hastalıklara neden olan lipit oksidasyonunu önlemede etkili olduğu sonucunu düşündürmektedir. Benzer çalışmalarda da $P$. europea'nın toksin grubuna göre oldukça etkili düzeyde MDA-TBA seviyesini düşürdüğü bildirilmiştir (Manyakara 2009). Ayrıca; K, FeCl, PLM gruplarında sırasıyla 18:1 yağ asitleri $3.25,3.09,3$ $\mu \mathrm{mol} / \mathrm{mL}, 18: 2$ yağ asitleri ise $8.62,8.07,7.98 \mu \mathrm{mol} / \mathrm{mL}$ olarak belirlenmiştir. PLM'nin in vitro ortamda metil esterleri üzerine etkisi araştırıldığında ise $P$. europea'nın metil esterlerinin korunmadığı görülmüştür $\quad(p>0.05)$. Bu durumun Plumbago türlerinde tespit edilen toksik etkiden kaynaklandığı düşünülmektedir. Yapılan bir çalışmada $P$. zeylanica'nın sitotoksisitesi araştırılmış sitotoksik etkileri olduğu tespit edilmiştir (Arunachalam ve ark. 2010).

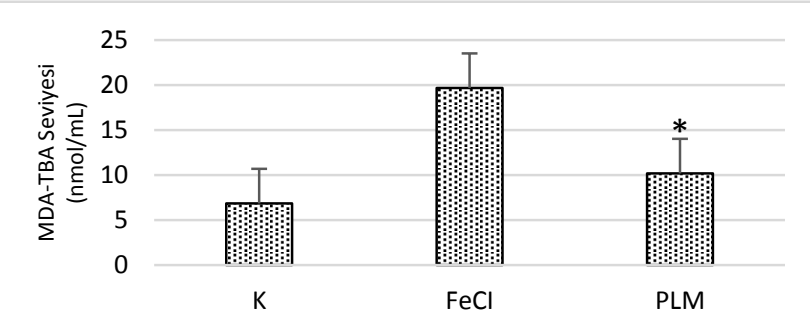

Şekil 2. P.europea' nın MDA-TBA üzerine etkisi ( $\mathrm{nmol} / \mathrm{mL}$ ) $(*: p<0.05)$.

\section{P. europea'nın Antimikrobiyal Aktivitesi}

P. europea'nın, değişik test grupları üzerindeki etkilerinin, control grubuna kıyasla etkili olduğu, bu etkinin maya ve dermofit funguslardan ziyade, bakteri grupları üzerinde daha belirgin olduğu saptandı (Tablo 2). En yüksek oranda etkiyi, $S$. aureus üzerinde göstermiştir. Benzer çalışmalarda ise, $P$. zeylanica'nın $10 \mathrm{mg} / \mathrm{mL}$ etanol ekstraktının S. aureus'da $15 \mathrm{~mm}, E$. coli'de ise $12 \mathrm{~mm}$ olarak tespit edilmiştir (Mittal ve Sharma 2010). P. zeylanica'nın kök ekstraktı ve plumbagin maddesinin E. coli, Salmonella typhi ve $S$. aureus' e karşı etkili olduğu belirlenmiştir (Jeyachandran ve ark. 2009). Benzer bir çalışma da ise $P$. zeylanica'nın çok iyi antimikrobiyal aktivite gösterdiği (Jetty ve ark. 2010), ayrıca, P. scandens'in M. tuberculosis ve $M$. tuberculosis MDR suşlarına karşı güçlü bir aktivite gösterdiği, MIC değerlerinin, 0.65 ile $1.3 \mathrm{mg} / \mathrm{mL}$ arasında değiştiği bildirilmiştir (Moncada Ascencio ve ark. 2011). Elde edilen değişik sonuçların temel nedeninin ise, bitki yapısındaki flavonoid, vitamin ve sterol gibi fitokimyasallardan (Tablo 1) kaynaklanabilir.

Tablo 1. P. europea' nın antimikrobiyal aktivitesi (mm).

\begin{tabular}{lcccc}
\hline Gruplar & S. aureus & E.coli & C.albicans & E. spp. \\
\hline Metanol & 8 & - & - & - \\
P. europea & 23 & 15 & 11 & - \\
\hline
\end{tabular}

Sonuç olarak; bitkiler üzerinde yapılan bu çalışmanın doğal antioksidanların ve antimikrobiyallerin kullanımına yönelik araştırmalara ışık tutacağını düşünmekteyiz. Daha etkin ve daha düşük yan etkiye sahip doğal antioksidanların ve antimikrobiyallerin tespit edilmesi, etkilerinin ortaya konulması ve yaşam kalitesi açısından önemli beklentiler arasında yer almaktadır.

\section{TEŞEKKÜR}

Bu çalışma FÜBAP 2118 nolu proje ile desteklenmiştir. HPLC ve gaz kromotografisi çalışmalarında desteklerini sağlayan Prof. Dr. Ökkeş Yılmaz'a teşşekkür ederiz. 


\section{KAYNAKLAR}

Ajayi G O, Olagunju J A, Ademuyiwa O ve Martins O C (2011) Gas Chromatography-Mass Spectrometry Analysis and Phytochemical Screening of Ethanolic Root Extract of Plumbago zeylanica, Linn. J Med Plants Res 5:1756-61

Akan H, Korkut M M ve Balos M M (2008) Arat Dağı ve Çevresinde (Birecik, Şanlıurfa) Etnobotanik Bir Araştırma. Fırat Üniversitesi Fen ve Mühendislik Bilimleri Dergisi 20:6781

Anonymous (1999) NCCLS (National Committee for Clinical Laboratory Standards). Performance Standards for Antimicrobial Susceptibility Testing, The 9th International Supplement, M100-S9, Villanova, P A.

Arunachalam K D, Velmurugan P ve Raja R B (2010) AntiInflammatory and Cytotoxic Effects of Extract from Plumbago zeylanica. Afri. J. Micribiol. Res 4:1239-45

Baytop T (1984) Türkiyede Bitkiler lle Tedavi (geçmişte ve Bugün). İstanbul Üniv.Yay.,No:3255, Eczacılık Fak., No:40, İstanbul

Brand-Williams W, Cuvelier M E E ve Berset C (1995) Use of a Free Radical Method to Evaluate Antioxidant Activity. LWT Food Science and Technology 28(1):25-30

Bulut G ve Tuzlacı E (2011) Folk Medicinal Plants of Bayramiç (Çanakkale-Turkey). Journal of Faculty Pharmacy of Istanbul University 40:87-100

Chromatography A (2004) A grace company catolog 600. Alltech Associates Inc, U.S

Collins C M ve Lyne P M (1987) Microbiological Methods Butter Morths \& Co (Publishers) Ltd. London. 450pp

Erden Y ve Kırbağ S (2013) Chemical and Biological Activities of Some Scorzonera Species: An In Vitro Study. Proceedings of the National Academy of Sciences, India Section B: Biological Sciences 85(1):319-326

Erden Y, Kırbağ S ve Yılmaz Ö (2013) Phytochemical Composition and Antioxidant Activity of Some Scorzonera Species. Proceedings of the National Academy of Sciences, India Section B: Biological Sciences, 83(2):271-276

Harborne J B (1967) Comparative Biochemistry of the Flavonoids-IV: Correlations between Chemistry, Pollen Morphology and Systematics in the Family Plumbaginaceae. Phytochemistry 6(10):1415-28

Helrich K (1990) Official Methods of Analysis of the Association of Official Analytical Chemists. Association of Official Analytical Chemists Arlington

Hsu B, Coupar IM ve Ng K (2006) Antioxidant Activity of Hot Water Extract from the Fruit of the Doum Palm, Hyphaene Thebaica. Food Chemistry, 98(2):317-328

Hung H C, Joshipura K J, Jiang R, Hu F B, Hunter D, Smith-Warner $S A$, ve Willett W C (2004) Fruit and vegetable intake and risk of major chronic disease. Journal of the National Cancer
Institute, 96(21):1577-1584

Lopez-Cervantes J, Sanchez-Machado D I, Rios-Vazquez N J (2006) High-performance liquid chromatography method for the simultaneous quantification of retinol, alpha-tocopherol, and cholesterol in shrimp waste hydrolysate. J Chromatogr A 1105(1-2):135-139

Jetty A, Subhakar C, Rajagopal D, Jetty M, Subramanyam M, ve Marthanda Murthy M (2010) Antimicrobial activities of neoand 1-epineo-isoshinanolones from Plumbago zeylanica roots. Pharmaceutical biology, 48(9):1007-1011

Jeyachandran R, Mahesh A, Cindrella L, Sudhakar S, ve Pazhanichamy K (2009) Antibacterial Activity of Plumbagin and Root Extracts of Plumbago Zeylanica L. Acta Biologica Cracoviensia Series Botanica 51(1):17-22

Justesen U (2000) Negative Atmospheric Pressure Chemical Ionisation Low-Energy Collision Activation Mass Spectrometry for the Characterisation of Flavonoids in Extracts of Fresh Herbs. Journal of chromatography. A 902(2):369-79

Manyakara B (2009) Antioxidant Properties of Plumbago Auriculata Lam. Doktora Tezi, North-West University.

Vineet $M$ ve Sharma SK An In Vitro Anti Microbial Activity of Callus and Root Extracts of Plumbago zeylanica Linn. in Various Test Microorganism. International Journal of Pharmaceutical Sciences Review and Research, 5(2):01-04

Moncada Ascencio N, Farcio Villarreal M, Rojas Idrogo C, Trevisan Ferreira D, Horna Davila O, Pereira J ve Delgado Paredes G E (2011) Biological activity of Plumbago scandens L. against multidrug-resistance strains of Mycobacterium tuberculosis. Boletín Latinoamericano y del Caribe de Plantas Medicinales y Aromáticas, 10(3):233-245

Nile Shivraj H ve Khobragade C N (2010) Antioxidant Activity and Flavonoid Derivatives of Plumbago zeylanica. J Nat Prod 3(2010):130-33

Ntambi J M (1999) Regulation of Stearoyl-CoA Desaturase by Polyunsaturated Fatty Acids and Cholesterol. Journal of lipid research 40(9):1549-58

Okoli C O, Akah P A, ve Ezugworie U (2006) Anti-Inflammatory Activity of Extracts of Root Bark of Securidaca Longipedunculata Fres (Polygalaceae). Afr. J. Trad. CAM 2(3):54-63

Pawar R K, Sharma S, Singh K C, ve Sharma R K R (2011) PhysicoChemical Standardisation and Development of HPTLC Method for the Determination of Plumbagin in Kalmegh Navayas Loha-an Ayurvedic Formulation. Int J Curr Pharm Res 3(1):43-48

Ronald, B P (2001) Spectrophotometric measurement of secondary lipid oxidation products. Current Protocols in Food Analytical Chemistry Spectrophotometric measurement of secondary lipid oxidation products. Current Protocols in Food Analytical Chemistry 2(4):1-8 
Sanchez-Moreno C, Larrauri J A, Saura-Calixto F (1999) Free radical scavenging capacity and inhibition of lipid oxidation of wines, grape juices and related polyphenolic constituents. Food Res Int 32(6):407-412

Serrilli A M, Sanfilippo V, Ballero M, Sanna C, Poli F, Scartezzini P, ve Bianco A (2010) Polar and Antioxidant Fraction of Plumbago Europaea L., a Spontaneous Plant of Sardinia. Natural product research 24(7):633-639

Shimoi K, Masuda S, Furugori M, Esaki S, ve Kinae N (1994) Radioprotective Effect of Antioxidative Flavonoids in Gamma-Ray Irradiated Mice. Carcinogenesis 15(11):26692672

Sokół-Łętowska A, Oszmiański J, and Wojdyło A (2007) Antioxidant Activity of the Phenolic Compounds of Hawthorn, Pine and Skullcap. Food Chemistry 103(3):85359

Tripoli E, La Guardia M, Giammanco S, Di Majo D, ve Giammanco M (2007) Citrus Flavonoids: Molecular Structure, Biological Activity and Nutritional Properties: A Review. Food
Chemistry 104(2):466-479

Uma D P, Soloman F E, ve Sharda A C (1999) Indian Medicinal Plants and Their Roots. Pharmaceut Biol 37:231-36.

Wang J, Ding L, Xu Y, Zhao X, Sun M, Liu Y, ... ve Lu L (2014) Determination of Inorganic Element Concentrations in the Roots of Plumbago zeylanica L. Analytical Letters 47(5):85570

Zahin M, Farrukh A, ve Ahmad I (2009) The in Vitro Antioxidant Activity and Total Phenolic Content of Four Indian Medicinal Plants. International Journal of pharmacy and pharmaceutical Sciences 1(1):88-95

Zu Y, Chunying L, Yujie F, ve Chunjian Z (2006) Simultaneous Determination of Catechin, Rutin, Quercetin Kaempferol and Isorhamnetin in the Extract of Sea Buckthorn (Hippophae rhamnoides L.) Leaves by RP-HPLC with DAD. Journal of pharmaceutical and biomedical analysis 41(3):714-19 